\title{
Chromosome-Scale Genome Assembly of Talaromyces rugulosus W13939, a Mycoparasitic Fungus and Promising Biocontrol Agent
}

\author{
Bo Wang, ${ }^{1}$ Li Guo, ${ }^{1,2}$ Kai Ye, ${ }^{1,2, \dagger}$ and Long Wang ${ }^{3, \dagger}$ \\ ${ }^{1}$ MOE Key Laboratory for Intelligent Networks \& Network Security, Faculty of Electronic and Information \\ Engineering, Xi'an Jiaotong University, Xi'an 710049, China \\ ${ }^{2}$ School of Life Science and Technology, Xi'an Jiaotong University, Xi'an 710049, China \\ ${ }^{3}$ State Key Laboratory of Mycology, Institute of Microbiology, Chinese Academy of Sciences, Beijing \\ 100101, China
}

\begin{abstract}
Here, we report a chromosome-level genome assembly of Talaromyces rugulosus (syn. Penicillium rugulosum) W13939 (six chromosomes; contig N50: $5.90 \mathrm{Mb}$ ), generated using a combination of PacBio long-read and lllumina paired-end data. $T$. rugulosus is not only a potent enzyme producer, but also a mycoparasite of Aspergillus flavus, which is a notorious plant pathogen and mycotoxin producer, making it a promising biocontrol agent. The $T$. rugulosus genome is rich in genes encoding proteases, carbohydrate-active enzymes, fungal cell wall-degrading enzymes, lectin, and secondary metabolite biosynthetic enzymes, reflecting its mycoparasitic life style and mycotoxigenic capability. This high-quality assembly of the $T$. rugulosus genome will be a valuable resource to assist us in the understanding of the molecular basis of mycoparasitism and facilitate the agricultural and biotechnological applications of Talaromyces spp.
\end{abstract}

\section{Genome Announcement}

Biological control agents significantly reduce the incidence of plant diseases caused by pathogenic fungi (Abdel-Rahim and Abo-Elyousr 2018; Abo-Elyousr et al. 2014; Freimoser et al. 2019). Various mechanisms such as mycoparasitism, niche and nutrient competition, antibiotics production, or priming plant defense responses contributed to biocontrol effects (Benítez et al. 2004; Guzmán-Guzmán et al. 2019; Harman 2006). Since Trichoderma spp. were recognized as mycoparasitic fungi by Weindling (1932), several mycoparasites, such as Talaromyces flavus (Madi et al. 1997), Chaetomium globosum (Moya et al. 2016), Alternaria alternata (Zheng et al. 2017), Pythium periplocum (Kushwaha et al. 2017), and T. pinophilus (Abdel-Rahim and Abo-Elyousr 2018), have been reported as promising biocontrol agents against phytopathogenic fungi for crop disease management. As a member of Talaromyces section Islandici, $T$. rugulosus W13939, isolated from air in Beijing, China, grows slowly on artificial culturing media, but when parasitizing Aspergillus flavus colonies, it creeps fast to overgrow entire colonies of $A$. flavus in 7 days (Fig. $1 \mathrm{~A}$ and $\mathrm{B}$ ). In addition, $T$. rugulosus is a potent producer of industrial enzymes such as beta-rutinosidase, phosphatase (Reyes et al.

\footnotetext{
${ }^{\dagger}$ Corresponding authors: K. Ye; kaiye@xjtu.edu.cn and L. Wang; wl_dgk@sina.com
}

Bo Wang and Li Guo contributed equally.

The author(s) declare no conflict of interest.

Accepted for publication 16 September 2020.

(C) 2020 The American Phytopathological Society

\section{Funding}

This project was supported by the National Natural Science Foundation of China (31701739, 31750001, 31970317), Fundamental Research Fund of Xi'an Jiaotong University, National Key R\&D Program of China (2018YFC0910400), Chinese Academy of Sciences (QYZDY-SSWSMC029) and China Postdoctoral Science Foundation (2020M673420).

\section{Keywords}

biocontrol, chromosome, filamentous ascomycetes, genome assembly, mycoparasitism 

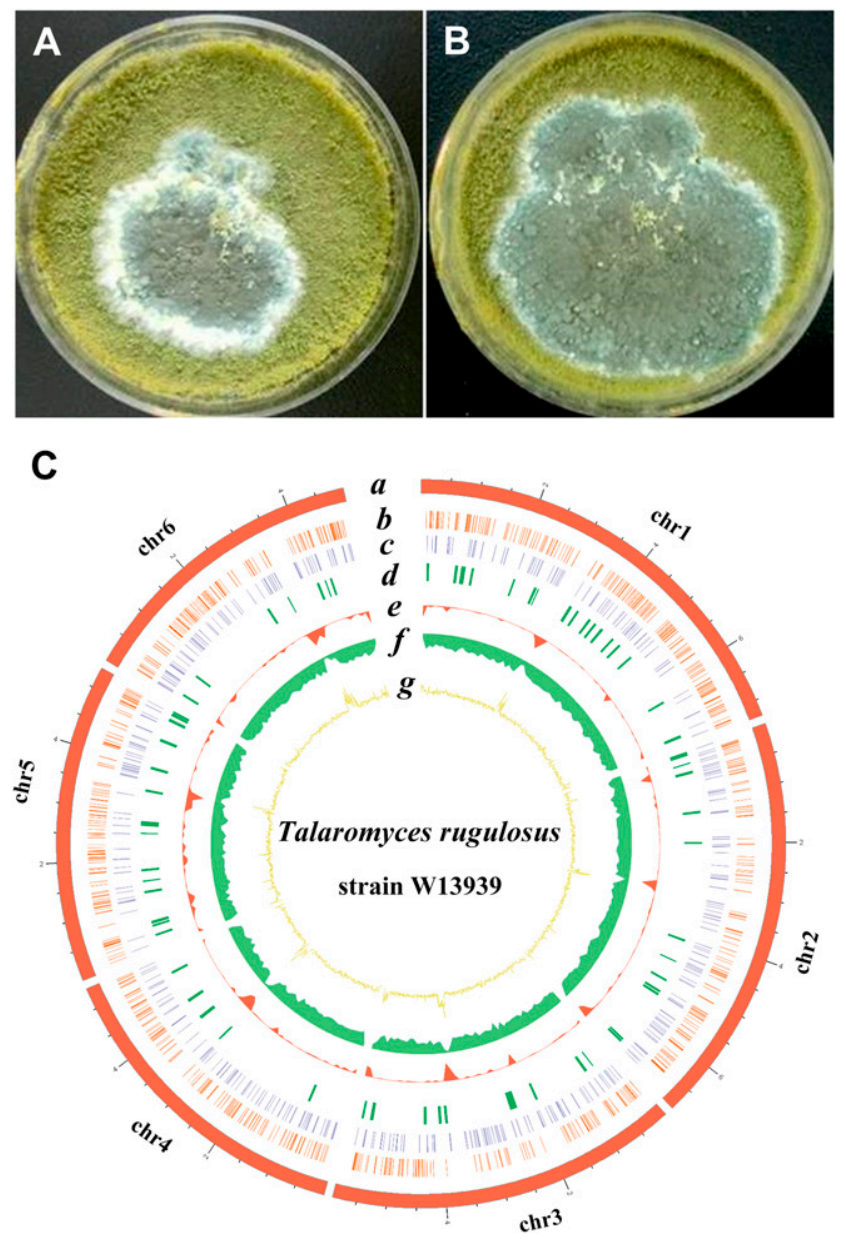

Fig. 1. The mycoparasitic morphology and genome features of Talaromyces rugulosus W13939. A, T rugulosus parasitizing the colony of Aspergillus flavus on malt extract agar (MEA) at $25^{\circ} \mathrm{C}$ after 7 days. B, $T$. rugulosus parasitizing the colony of $A$. flavus on MEA at $25^{\circ} \mathrm{C}$ after 14 days. C, The six chromosomes of $T$. rugulosus genome features. Tracks a to $g$ represent the distribution of karyotype, carbohydrateactive enzymes, proteases, secondary metabolite biosynthetic genes, density of transposable elements, gene density, and GC density, respectively, with densities calculated in 100-Kb windows ( $e$ to $f$ ) and $10-\mathrm{Kb}$ windows $(g)$.

1999; Narikawa et al. 2000), and secondary metabolites, including skyrin and rugulosin, with antibiotism against Staphylococcus aureus (Breen et al. 1955; Yamazaki et al. 2010). Furthermore, $T$. rugulosus strains colonize the maize rhizosphere and stimulate plant growth, increasing dry matter yields by 3.6 to $28.6 \%$ (Reyes et al. 2002). Genome sequencing and assembly have been reported for several mycoparasitic species (Karlsson et al. 2015, 2017; Kubicek et al. 2011; Li et al. 2017; Zhao et al. 2020). However, a genomic resource of T. rugulosus remains lacking, impeding our exploitation of its mycoparasitic and plant growth stimulation effects. Thus, decoding the $T$. rugulosus genome will provide a valuable resource not only in facilitating dissection of mycoparasitic and biocontrol mechanisms but, also, contributing to comparative genomic studies toward understanding the genome evolution of mycoparasitic fungi. Seven-day-old $T$. rugulosus mycelia were collected to extract high molecular weight genomic DNA using the CTAB (cetyl trimethyl ammonium bromide) method. A total of $4.88 \mathrm{~Gb}$ of paired-end short sequence reads $(2 \times 150 \mathrm{bp}$; average fragment size: $400 \mathrm{bp}$; Illumina NovaSeq 6000 platform) and $18.42 \mathrm{~Gb}$ of single-molecule long-read sequence reads (read length N50: 23,169 bp; PacBio SMRT RS II platform) were generated. A Jellyfish-GenomeScope pipeline using Illumina reads (133x coverage) with '-m 17' (Marçais and Kingsford 2011; Vurture et al. 2017) revealed an estimated genome size of $35.94 \mathrm{Mb}$ for $T$. rugulosus (haploid). We then assembled a $T$. rugulosus genome from the PacBio reads (526x coverage), using the long-read assembler NextDenovo v2.0 with parameters 
Table 1. Summary of the genome assembly and annotation statistics ${ }^{a}$

\begin{tabular}{lccc} 
Strains & T. rugulosus & T. pinophilus & Trichoderma atroviride \\
Number of contigs & 6 & 8 & 29 \\
Number of chromosomes & 6 & 8 & NA \\
Genome size (Mb) & 36.76 & 36.48 & 36.14 \\
GC content (\%) & 46.92 & 46.25 & 49.75 \\
Contig N50 (bp) & $5,896,210$ & $4,804,168$ & $2,007,903$ \\
Number of protein-coding genes & 11,907 & 12,402 & 11,816 \\
Repeat content (\%) & 2.52 & 1.35 & 1.29 \\
Proteases & 391 & 390 & 378 \\
Secondary metabolite biosynthetic genes & 67 & 59 & 30 \\
Carbohydrate-active enzymes & 741 & 761 & 663 \\
Fungal cell wall-degrading enzymes & 107 & 81 & 101 \\
Lectin & 8 & 5 & 8 \\
\hline
\end{tabular}

a Talaromyces rugulosus W13939 compared with mycoparasitic T. pinophilus (GenBank accession: GCA_001571465.2) (Abdel-Rahim and AboElyousr 2018; Li et al. 2017) and mycoparasitic Trichoderma atroviride (GenBank accession: GCA_000171015.2) (Kubicek et al. 2011). NA = unavailable.

b Repeat contents were identified by the same pipeline (this study) to ensure a fair comparison.

'read_cutoff $=1 \mathrm{k}$ ' and 'seed_cutoff $=45,821$ '. Pilon v. 1.22 with parameters '-changesvcf-frags' (Walker et al. 2014) was used to polish the PacBio assembly, and a total of 2,734 $(0.008 \%)$ erroneous positions were corrected. The contig N50 before correction and after correction was 5,896,623 and 5,896,210 bp, respectively. BUSCO v. 1.22 with parameters '-m all -I fungi_odb9' (benchmarking universal single copy ortholog) (Simão et al. 2015) was used to assess the $T$. rugulosus genome assembly completeness. The BUSCO scores for the genome before and after correction were 95 and $96 \%$, respectively. These results showed that the error correction by using Illumina reads improved the assembly completeness. The final assembly of the $T$. rugulosus genome was $36.76 \mathrm{Mb}$, consisting of six contigs (N50: 5.90 $\mathrm{Mb})$, close to its estimated genome size. A telomeric repeat unit $($ TTAGGG) $(n>3)$ was present on both ends of five contigs (chromosomes) and only on the $3^{\prime}$ end of chromosome 4, whose $5^{\prime}$ end was filled with rDNA units. Each chromosome is represented as a single contig, demonstrating that the $T$. rugulosus genome assembly is high-quality at the chromosome level (Fig. 1C). The regions with low GC content (AT-rich blocks) are rich in transposable elements, frequently found in intergenic, putative centromeric and telomeric regions (Fig. 1C). In model fungi, such as Neurospora crassa and Saccharomyces cerevisiae, AT-rich blocks play an important role in mediating chromatin structure and chromosomal contacts (Aramayo and Selker 2013; Blat and Kleckner 1999; Galazka et al. 2016). These findings provide a valuable resource for future centromere and chromosome architecture studies in the mycoparasitic fungus $T$. rugulosus.

For $T$. rugulosus genome annotation, de novo gene structure was predicted by GeneMark-ES with parameters '-ES-fungus' (Borodovsky and Lomsadze 2011). A T. marneffei gene model (GenBank assembly accession GCA_009650675.1) (Cuomo et al. 2020) was then used to train Augustus v. 3.1 (Stanke and Morgenstern 2005). MAKER2 pipeline (Cantarel et al. 2008), with the RepeatMasker v. 4.0.7 (Tarailo-Graovac and Chen 2009) option on to find and mask repetitive elements, was used to find protein-coding genes, integrating gene models predicted from GeneMark-ES and Augustus, and protein sequences of $T$. islandicus (GenBank assembly accession GCA_000985935.1), a close relative of $T$. rugulosus (Schafhauser et al. 2015). In total, the T. rugulosus genome has 11,907 proteincoding genes and $2.52 \%$ repeat content (Table 1). The final BUSCO score of $100 \%$ based on the 'fungi_odb9' library suggests a complete $T$. rugulosus genome assembly (Fig. 1C).

Carbohydrate-active enzymes (CAZymes) and fungal cell wall-degrading enzymes (FCWDEs) were classified using the dbCAN classification system with an E-value threshold of 1e-5 (Amselem et al. 2011; Yin et al. 2012). Putative secondary metabolite key biosynthetic genes were identified by antiSMASH v. 5.0 (Blin et al. 2019). Proteases were identified by the MEROPS database (Rawlings et al. 2018). Candidate lectins were identified by Hmmscan with PFAM domains PF00652, PF01419, PF03388, PF09458, and PF14200. We found that $T$. rugulosus was particularly well-equipped with genes encoding proteases, CAZymes, FCWDEs, lectin, and secondary metabolite biosynthetic enzymes. The CAZymes content in $T$. rugulosus (741) was smaller than that of the mycoparasitic fungus T. pinophilus (761) but 
larger than that of Trichoderma atroviride (663) (Table 1). The proteases (391) and FCWDEs (107) content in T. rugulosus was larger than those of the other two species (Table 1), suggesting $T$. rugulosus may have stronger mycoparasitic ability. This high-quality genome assembly and annotation of $T$. rugulosus will be a useful resource for fungal comparative genomics to elucidate the evolution of mycoparasitism and functional genomic studies of T. rugulosus, for its industrial use and biocontrol effects against plant pathogens. The genome project has been deposited at GenBank under the BioProject ID PRJNA639236. The six chromosomal sequences and gene annotations of $T$. rugulosus are indexed at GenBank with accession numbers CP055898 through CP055903. PacBio reads and Illumina reads are available in the National Center for Biotechnology Information Sequenced Read Archive under accession numbers SRR12007734 and SRR12007532, respectively.

\section{Acknowledgments}

We thank the anonymous reviewers for their kind and helpful comments on the original manuscript.

\section{Author-Recommended Internet Resource}

NextDenovo v2.0: https://github.com/Nextomics/NextDenovo

\section{Literature Cited}

Abdel-Rahim, I. R., and Abo-Elyousr, K. A. M. 2018. Talaromyces pinophilus strain AUN-1 as a novel mycoparasite of Botrytis cinerea, the pathogen of onion scape and umbel blights. Microbiol. Res. 212-213:1-9.

Abo-Elyousr, K. A. M., Abdel-Hafez, S. I. I., and Abdel-Rahim, I. R. 2014. Isolation of Trichoderma and evaluation of their antagonistic potential against Alternaria porri. J. Phytopathol. 162:567-574.

Amselem, J., Cuomo, C. A., van Kan, J. A., Viaud, M., Benito, E. P., Couloux, A., Coutinho, P. M., de Vries, R. P., Dyer, P. S., Fillinger, S., Fournier, E., Gout, L., Hahn, M., Kohn, L., Lapalu, N., Plummer, K. M., Pradier, J. M., Quévillon, E., Sharon, A., Simon, A., ten Have, A., Tudzynski, B., Tudzynski, P., Wincker, P., Andrew, M., Anthouard, V., Beever, R. E., Beffa, R., Benoit, I., Bouzid, O., Brault, B., Chen, Z., Choquer, M., Collémare, J., Cotton, P., Danchin, E. G., Da Silva, C., Gautier, A., Giraud, C., Giraud, T., Gonzalez, C., Grossetete, S., Güldener, U., Henrissat, B., Howlett, B. J., Kodira, C., Kretschmer, M., Lappartient, A., Leroch, M., Levis, C., Mauceli, E., Neuvéglise, C., Oeser, B., Pearson, M., Poulain, J., Poussereau, N., Quesneville, H., Rascle, C., Schumacher, J., Ségurens, B., Sexton, A., Silva, E., Sirven, C., Soanes, D. M., Talbot, N. J., Templeton, M., Yandava, C., Yarden, O., Zeng, Q., Rollins, J. A., Lebrun, M. H., and Dickman, M. 2011. Genomic analysis of the necrotrophic fungal pathogens Sclerotinia sclerotiorum and Botrytis cinerea. PLoS Genet. 7:e1002230.

Aramayo, R., and Selker, E. U. 2013. Neurospora crassa, a model system for epigenetics research. Cold Spring Harb. Perspect. Biol. 5:a017921.

Benítez, T., Rincón, A. M., Limón, M. C., and Codón, A. C. 2004. Biocontrol mechanisms of Trichoderma strains. Int. Microbiol. 7:249-260.

Blat, Y., and Kleckner, N. 1999. Cohesins bind to preferential sites along yeast chromosome III, with differential regulation along arms versus the centric region. Cell 98:249-259.

Blin, K., Shaw, S., Steinke, K., Villebro, R., Ziemert, N., Lee, S. Y., Medema, M. H., and Weber, T. 2019. antiSMASH 5.0: Updates to the secondary metabolite genome mining pipeline. Nucleic Acids Res. 47 (W1):W81-W87.

Borodovsky, M., and Lomsadze, A. 2011. Eukaryotic gene prediction using GeneMark.hmm-E and GeneMark-ES. Curr. Protoc. Bioinf. 4:4.6.1-4.6.10.

Breen, J., Dacre, J. C., Raistrick, H., and Smith, G. 1955. Studies in the biochemistry of micro-organisms. 95. Rugulosin, a crystalline colouring matter of Penicillium rugulosum Thom. Biochem. J. 60:618-626.

Cantarel, B. L., Korf, I., Robb, S. M., Parra, G., Ross, E., Moore, B., Holt, C., Sánchez Alvarado, A., and Yandell, M. 2008. MAKER: An easy-to-use annotation pipeline designed for emerging model organism genomes. Genome Res. 18:188-196.

Cuomo, C. A., Shea, T., Nguyen, T., Ashton, P., Perfect, J., and Le, T. 2020. Complete genome sequences for two Talaromyces marneffei clinical isolates from northern and southern Vietnam. Microbiol. Resour. Announc. 9:e01367-19.

Freimoser, F. M., Rueda-Mejia, M. P., Tilocca, B., and Migheli, Q. 2019. Biocontrol yeasts: Mechanisms and applications. World J. Microbiol. Biotechnol. $35: 154$.

Galazka, J. M., Klocko, A. D., Uesaka, M., Honda, S., Selker, E. U., and Freitag, M. 2016. Neurospora chromosomes are organized by blocks of importin alphadependent heterochromatin that are largely independent of H3K9me3. Genome Res. 26:1069-1080.

Guzmán-Guzmán, P., Porras-Troncoso, M. D., Olmedo-Monfil, V., and HerreraEstrella, A. 2019. Trichoderma species: Versatile plant symbionts. Phytopathology 109:6-16.

Harman, G. E. 2006. Overview of mechanisms and uses of Trichoderma spp Phytopathology 96:190-194.

Karlsson, M., Atanasova, L., Jensen, D. F., and Zeilinger, S. 2017. Necrotrophic mycoparasites and their Genomes. Pages 1005-1026 in: The Fungal Kingdom. J. Heitman, B. J. Howlett, P. W. Crous, E. H. Stukenbrock, T. Y. James, and N. A. R. Gow, eds. American Society for Microbiology, Washington, D.C.

Karlsson, M., Durling, M. B., Choi, J., Kosawang, C., Lackner, G., Tzelepis, G. D., Nygren, K., Dubey, M. K., Kamou, N., Levasseur, A., Zapparata, A., Wang, J., Amby, D. B., Jensen, B., Sarrocco, S., Panteris, E., Lagopodi, A. L., Pöggeler, S., Vannacci, G., Collinge, D. B., Hoffmeister, D., Henrissat, B., Lee, Y. H., and Jensen, D. F. 2015. Insights on the evolution of mycoparasitism from the genome of Clonostachys rosea. Genome Biol. Evol. 7:465-480.

Kubicek, C. P., Herrera-Estrella, A., Seidl-Seiboth, V., Martinez, D. A., Druzhinina, I. S., Thon, M., Zeilinger, S., Casas-Flores, S., Horwitz, B. A., Mukherjee, P. K., Mukherjee, M., Kredics, L., Alcaraz, L. D., Aerts, A., Antal, Z., Atanasova, L., Cervantes-Badillo, M. G., Challacombe, J., Chertkov, O., McCluskey, K., Coulpier, F., Deshpande, N., von Döhren, H., Ebbole, D. J., Esquivel-Naranjo, E. U., Fekete, E., Flipphi, M., Glaser, F., Gómez-Rodríguez, E. Y., Gruber, S., Han, C., Henrissat, B., Hermosa, R., Hernández-Oñate, M., Karaffa, L., Kosti, I., Le Crom, S., Lindquist, E., Lucas, S., Lübeck, M., Lübeck, P. S., Margeot, A., Metz, B., Misra, M., Nevalainen, H., Omann, M., Packer, N., Perrone, G., Uresti-Rivera, E. E., Salamov, A., Schmoll, M., Seiboth, B., Shapiro, H., Sukno, S., TamayoRamos, J. A., Tisch, D., Wiest, A., Wilkinson, H. H., Zhang, M., Coutinho, P. M., Kenerley, C. M., Monte, E., Baker, S. E., and Grigoriev, I. V. 2011. Comparative genome sequence analysis underscores mycoparasitism as the ancestral life style of Trichoderma. Genome Biol. 12:R40.

Kushwaha, S. K., Vetukuri, R. R., and Grenville-Briggs, L. J. 2017. Draft genome sequence of the mycoparasitic oomycete Pythium periplocum strain CBS 532.74. Genome Announc. 5:e00057-00017. 
Li, C. X., Zhao, S., Zhang, T., Xian, L., Liao, L. S., Liu, J. L., and Feng, J. X. 2017. Genome sequencing and analysis of Talaromyces pinophilus provide insights into biotechnological applications. Sci. Rep. 7:490.

Madi, L., Katan, T., Katan, J., and Henis, Y. 1997. Biological control of Sclerotium rolfsii and Verticillium dahliae by Talaromyces flavus is mediated by different mechanisms. Phytopathology 87:1054-1060.

Marçais, G., and Kingsford, C. 2011. A fast, lock-free approach for efficient parallel counting of occurrences of k-mers. Bioinformatics 27:764-770.

Moya, P., Pedemonte, D., Amengual, S., Franco, M. E., and Sisterna, M. N. 2016. Antagonism and modes of action of Chaetomium globosum species group, potential biocontrol agent of barley foliar diseases. Bol. Soc. Argent. Bot. 51: 569-578.

Narikawa, T., Shinoyama, H., and Fujii, T. 2000. A beta-rutinosidase from Penicillium rugulosum IFO 7242 that is a peculiar flavonoid glycosidase. Biosci. Biotechnol. Biochem. 64:1317-1319.

Rawlings, N. D., Barrett, A. J., Thomas, P. D., Huang, X., Bateman, A., and Finn, R. D. 2018. The MEROPS database of proteolytic enzymes, their substrates and inhibitors in 2017 and a comparison with peptidases in the PANTHER database. Nucleic Acids Res. 46 (D1):D624-D632.

Reyes, I., Bernier, L., and Antoun, H. 2002. Rock phosphate solubilization and colonization of maize rhizosphere by wild and genetically modified strains of Penicillium rugulosum. Microb. Ecol. 44:39-48.

Reyes, I., Bernier, L., Simard, R., Tanguay, P., and Antoun, H. 1999. Characteristics of phosphate solubilization by an isolate of a tropical Penicillium rugulosum and two UV-induced mutants. FEMS Microbiol. Ecol. 28:291-295.

Schafhauser, T., Wibberg, D., Rückert, C., Winkler, A., Flor, L., van Pée, K. H., Fewer, D. P., Sivonen, K., Jahn, L., Ludwig-Müller, J., Caradec, T., Jacques, P., Huijbers, M. M., van Berkel, W. J., Weber, T., Wohlleben, W., and Kalinowski, J. 2015. Draft genome sequence of Talaromyces islandicus ("Penicillium islandicum") WF-38-12, a neglected mold with significant biotechnological potential. J. Biotechnol. 211:101-102.
Simão, F. A., Waterhouse, R. M., loannidis, P., Kriventseva, E. V., and Zdobnov, E. M. 2015. BUSCO: Assessing genome assembly and annotation completeness with single-copy orthologs. Bioinformatics 31:3210-3212.

Stanke, M., and Morgenstern, B. 2005. AUGUSTUS: A web server for gene prediction in eukaryotes that allows user-defined constraints. Nucleic Acids Res. 33: W465-W467.

Tarailo-Graovac, M., and Chen, N. 2009. Using RepeatMasker to identify repetitive elements in genomic sequences. Curr. Protoc. Bioinf. 5:4.10.1-4.10.14.

Vurture, G. W., Sedlazeck, F. J., Nattestad, M., Underwood, C. J., Fang, H., Gurtowski, J., and Schatz, M. C. 2017. GenomeScope: Fast reference-free genome profiling from short reads. Bioinformatics 33:2202-2204.

Walker, B. J., Abeel, T., Shea, T., Priest, M., Abouelliel, A., Sakthikumar, S., Cuomo, C. A., Zeng, Q., Wortman, J., Young, S. K., and Earl, A. M. 2014. Pilon: An integrated tool for comprehensive microbial variant detection and genome assembly improvement. PLoS One 9:e112963.

Weindling, R. 1932. Trichoderma lignorum as a parasite of other soil fungi. Phytopathology 22:837-845.

Yamazaki, H., Koyama, N., Omura, S., and Tomoda, H. 2010. New rugulosins, antiMRSA antibiotics, produced by Penicillium radicum FKI-3765-2. Org. Lett. 12: 1572-1575.

Yin, Y., Mao, X., Yang, J., Chen, X., Mao, F., and Xu, Y. 2012. dbCAN: A web resource for automated carbohydrate-active enzyme annotation. Nucleic Acids Res. 40 (W1):W445-W451.

Zhao, H., Zhou, T., Xie, J., Cheng, J., Chen, T., Jiang, D., and Fu, Y. 2020. Mycoparasitism illuminated by genome and transcriptome sequencing of Coniothyrium minitans, an important biocontrol fungus of the plant pathogen Sclerotinia sclerotiorum. Microb. Genom. 6:e000345.

Zheng, L., Zhao, J., Liang, X., Zhan, G., Jiang, S., and Kang, Z. 2017. Identifification of a novel Alternaria alternata strain able to hyperparasitize Puccinia striiformis f. sp. tritici, the causal agent of wheat stripe rust. Front. Microbiol. 8:71. 